\title{
Erratum
}

\section{Surgical management of trigeminal schwannomas: defining the role for endoscopic endonasal approaches}

To THE EDITOR: We appreciate publication of our article, "Surgical management of trigeminal schwannomas: defining the role for endoscopic endonasal approaches" (Neurosurg Focus 37(4):E17, 2014). After publication, we found two errors in the figures, specifically the MR images shown in Fig. 1 upper and Fig. 3 right.

We have replaced these two MR images in the article. The corrected Figs. 1 and 3 are shown below.
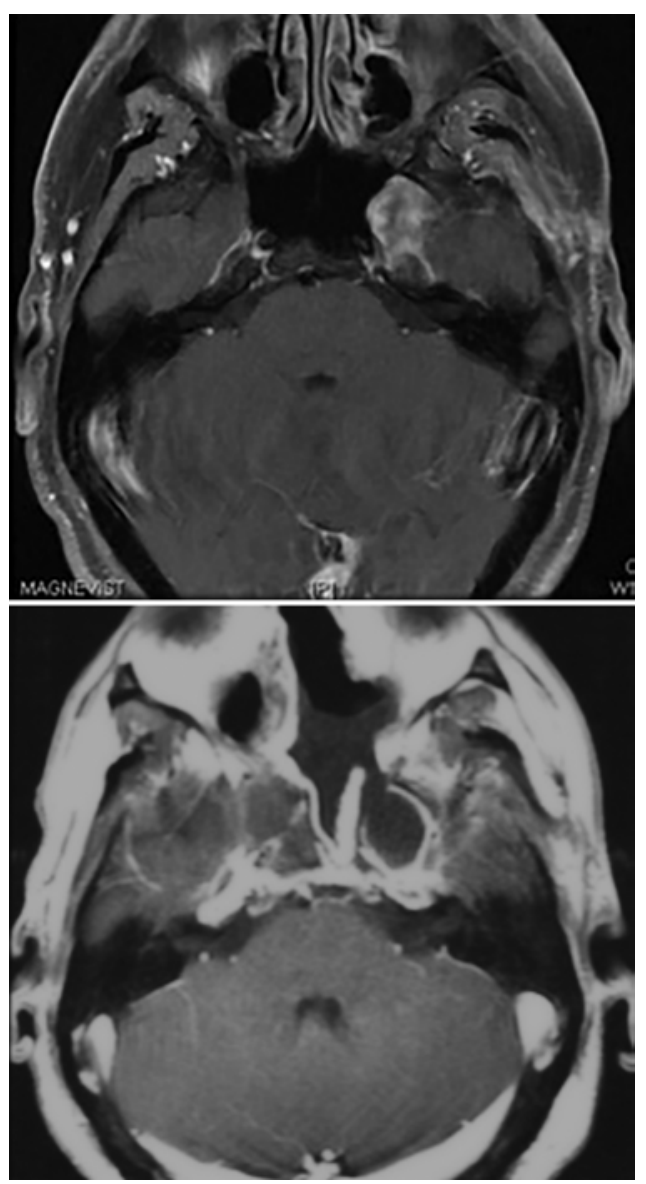

FIG. 1. Case 1. Upper: Preoperative T1-weighted MR image with contrast demonstrating an enhancing mass restricted to Meckel's cave. Lower: Postoperative T1-weighted MR image with contrast confirming gross-total resection.

Please include this information when citing this paper: DOI: 10.3171/2014.10.FOCUS14341a.
We apologize to the editor and readers for the errors, and we are pleased to have the opportunity to replace these figures. The correction was made as of November $1,2014$.

SHAAN M. RAZA, M.D. Theodore H. Schwartz, M.D. Weill Cornell Medical College New York, NY
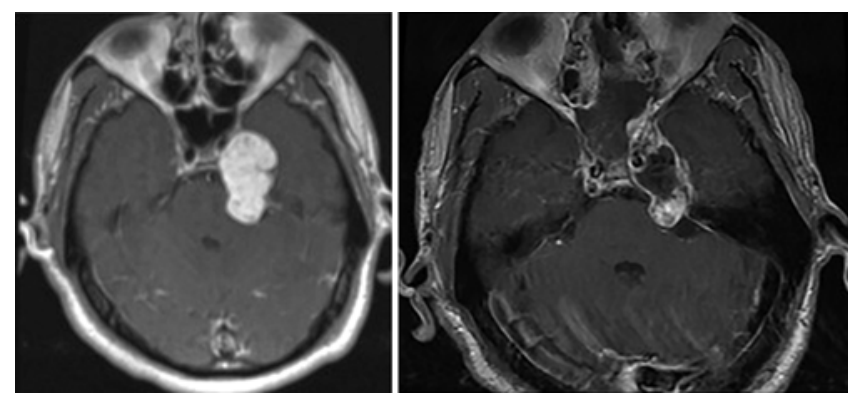

FIG. 3. Case 2. Left: Preoperative T1-weighted MR image with contrast demonstrating an enhancing mass within both Meckel's cave and the posterior fossa. Right: Postoperative T1-weighted MR image with contrast demonstrating residual disease in the posterior fossa. 